\title{
PENGABDIAN MASYARAKAT BAKTI SOSIAL BERBAGI PAKET "NASI PAHLAWAN" PEDULI COVID-19 DI GRAHA YATIM DAN DHUAFA KOTA CIREBON
}

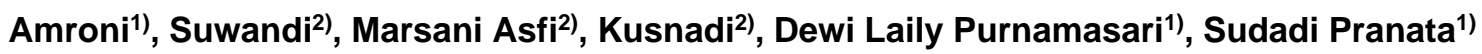 \\ 1)Prodi Manajemen Bisnis, FEB, Universitas Catur Insan Cendekia, Kota Cirebon, Jawa Barat, Indonesia \\ ${ }^{2)}$ Prodi Sistem Informasi, FTI, Universitas Catur Insan Cendekia, Kota Cirebon, Jawa Barat, Indonesia \\ Corresponding author: Amroni \\ E-mail : amroni@cic.ac.id
}

Diterima 15 November 2021, Direvisi 26 November 2021, Disetujui 26 November 2021

\begin{abstract}
ABSTRAK
Pengabdian masyarakat dalam rangka memperingati hari pahlawan tahun 2021 dilakukan oleh Himpunan Mahasiswa Manajemen Bisnis(HIMABIS) Universitas Catur Insan Cendekia berupa berbagi paket peduli Covid-19. Paket peduli tersebut disebut "Nasi Pahlawan". Berbagi kebahagian dalam rangka hari Pahlawan tersebut dilakukan HIMABIS dengan dosen bersama dengan anak-anak dari Graha Yatim dan Dhuafa Kota Cirebon serta tiga tempat lainnya. Pelaksanaan diawali dengan perencanaan kegiatan, pencarian sponsorship kegiatan, pelaksanaan pendistribusian paket serta evaluasi hasil kegiatan. Jumlah paket Nasi Pahlawan sebanyak 358 Paket nasi box. Tujuan pelaksanaan adalah selain menumbuhkan sikap peduli antar sesama masyarakat dalam masa pandemi, juga merupakan program rutin dari HIMABIS dan Universitas Catur Insan Cendekia. Diharapkan akan tumbuh jiwa kesetiakawanan sosial bagi seluruh sivitas akademika yang ada di UCIC.
\end{abstract}

Kata kunci: nasi pahlawan; HIMABIS; UCIC; PKM.

\begin{abstract}
Community service in commemoration of Hero's Day in 2021 is carried out by Himpunan Mahasiswa Manajemen Bisnis (HIMABIS) of Catur Insan Cendekia University in the form of sharing Covid-19 care packages. The care package is called "Nasi Pahlawan". HIMABIS shared the joy in celebrating Hero's Day with the lecturers along with children from Graha Yatim and Dhuafa, Cirebon City and three other places. Implementation begins with planning activities, seeking sponsorship of activities, implementing package distribution and evaluating the results of activities. The number of packages of Nasi Pahlawan is 358 box rice package. The purpose of the implementation is in addition to fostering a caring attitude among people during the pandemic, it is also a routine program from HIMABIS and Catur Insan Cendekia University. It is hoped that the spirit of social solidarity will grow for all academics at UCIC.
\end{abstract}

Keywords: nasi pahlawan; HIMABIS; UCIC; PKM.

\section{PENDAHULUAN}

Permasalahan ekonomi merupakan salah satu permasalahan yang sering dihadapi oleh masyarakat di masa pendemi Covid-19. Kondisi ini tentu saja dapat memberikan pengaruh pada kehidupan sosial serta kegiatan sehari-hari. Kondisi ini tidak hanya terjadi di desa tapi juga di masyarakat kota. Pandemi Covid-19 mengakibatkan perubahan pola kehidupan di masyarakat secara langsung. Wabah Corona ini menyebabkan berhentinya aktifitas perekonomian masyarakat. Aktitvitas-aktifitas industri berhenti dan juga terjadinya pengurangan jam operasional. Hal ini menyebabkan banyak masyarakat kehilangan pekerjaan maupun berkurangnya jam kerja. Pada akhirnya menyebabkan berkurangnya sumber pendapatan masyarakat.

Kegiatan bakti sosial atau baksos adalah kegiatan kepedulian untuk menumbuhkan rasa kemanusiaan terhadap sesama. Kegiatan baksos ini selain dapat menumbuhkan rasa kekerabatan dan silaturahim juga dapat memperkuat tali persaudaraan antar sesama. Pengabdian masyarakat $(\mathrm{Pkm})$ adalah suatu kegiatan yang berguna bagi masyarakat melalui beberapa aktivitas tanpa mengharapkan imbalan apapun (Wikipedia, 2021). Program Pkm di Universitas Catur Insan Cendekia diharapkan dapat memberikan kontribusi bagi masyarakat sehingga tercapai peningkatan kesejahteraan dan kemajuan bangsa Indonesia. Kegiatan Pengabdian Masyarakat (Pkm) adalah salah 
satu bagian dari Tri Dharma Perguruan Tinggi (Wikipedia, 2021).

Kegiatan Pkm di Universitas CIC dalam bentuk bakti sosial secara rutin sering dilaksanakan diantaranya melalui pemberian santunan untuk anak yatim di yayasan Kreasi Bangun Semesta cabang Cirebon (Suwandi et al., 2021). Kegiatan Pkm bakti sosial juga diadakan dalam rangka peringatan hari-hari besar nasional, seperti hari sumpah pemuda. Sedangkan bentuk kegiatan bakti sosial lainnya yang dilaksanakan oleh beberapa universitas dalam membantu masyarakat terdampak pandemi dilakukan di desa Jambeyan (AlFaruqi et al., 2020). Pemberian paket sembako untuk masyarakat yang terdampak pandemi Covid-19 juga dilakukan STIE Bima (Muniarty et al., 2021) serta pengabdian masyarakat oleh Mahasiswa Islam Universitas Flores (Arafat et al., 2021) serta pelaksanaan bakti sosial dalam membantu untuk mengurangi beban ekonomi masyarakat akibat wabah global covid-19 di lingkungan RW 011 kelurahan pengasinan kota Depok (Karlina et al., 2020).

Dalam memperingati hari Pahlawan 10 Nopember 2021, tema yang diusung oleh pemerintah adalah "Pahlawanku Insprirasiku". Peringatan hari Pahlawan dilakukan secara rutin oleh masyarakat Indonesia untuk mengenang jasa serta perjuangan para pahlawan dalam mengusir penjajah dari bumi Indonesia. Dengan peringatan hari pahlawan juga diharapkan juga bagaimana menanamkan nilai-nilai kepahlawanan kepada generasi saat ini dalam mengisi kemerdekaan Indonesia. Setiap insan masyarakat Indonesia harus senantiasa memiliki semangat kepahlawanan untuk membangun negeri berdasarkan potensi dan profesi masing-masing. Dengan hari pahlawan juga diharapkan dapat menggerakkan kesadaran masyarakat untuk meneladani melalui implementasi nilai-nilai kepahlawan dalam kehidupan sehari-hari, memperkokoh persatuan dan kesatuan bangsa berlandaskan semangat dan nilai kepahlawanan serta menumbuhkan serta meningkatkan rasa cinta serta bangga sebagai bangsa dan negara Indonesia (Kemensos, 2021).

Melalui tema tersebut maka sivitas akademika Universitas Catur Insan Cendekia (UCIC) melakukan kegiatan bakti sosial kepada anak-anak yatim dan dhuafa yang berada di sekitar kampus UCIC. Kegiatan bakti sosial ini diharapkan dapat membangun kebersamaan ditengah kehidupan masyarakat. Menjunjung nilai- nilai kepahlawanan dan menghormari jasa para pahlawan yang merupakan nilai yang harus tetap dilestarikan terutama generasi muda. Himpunan Mahasiswa (HIMA) dan
Badan Koordinasi Mahasiswa (BKM) UCIC adalah organisasi kemahasiswaan yang memayungi seluruh kegiatan kemahasiswaan baik secara keilmuan akademik maupun non akademik yang ada di Universitas Catur Insan Cendekia (UCIC). HIMA dan BKM berada dibawah pembinaan Biro Kemahasiswaan UCIC. BKM membawahi HIMA dan UKM-UKM baik UKM yang bersifat akademik atau keilmuan, nalar tapi juga non akademik serta kerohanian (Cic.ac.id, 2021).

Graha Yatim dan Dhu'afa atau disingkat dengan Gray merupakan yayasan sosial yang bergerak dalam bidang Kesejahteraan Sosial. GRAY memberikan santunan kepada anak-anak yatim dan dhu'afa, pendidikan dan pemeliharaan anak asuh. Beberapa program yang dilaksanakan oleh Gray diantaranya adalah program Sosial kemanusiaan, program pendidikan, program ekonomi,kesehatan, ramadhan, dakwah keagamaan dan layanan kemasyarakatan.

Kantor cabang GRAY berada di beberapa Kota di Indonesia, yaitu : Cirebon, Kuningan, Jakarta, Bekasi, Surabaya dan Kalimantan Selatan. Sejak Juni 2009, Yayasan Harapan Robbani yang menaungi GRAY memiliki asrama yang beralamat di Jl. Kesambi Dalam No. 15/95, RT/RW 01/04, Kel. Drajat, Kec. Kesambi, Kota Cirebon. Adapun Surat Keterangan Domisili Asrama No. 1554/Kel.Drj/VI/2009. Yayasan Harapan Robbani yang menaungi GRAY adalah organisasi independen, tanpa terafiliasi dengan Organisasi Politik, Organisasi Agama atau Organisasi lainnya. Berdiri karena kepedulian masyarakat terhadap anak-anak yang membutuhkan perlindungan, pendidikan dan kesejahteraan (GRAY, 2021).

\section{METODE}

Secara garis besar metode kegiatan pkm dengan bakti sosial ini terdiri dari tiga kegiatan utama, seperti pada Gambar 1.

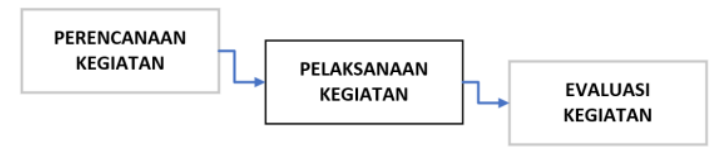

\section{Gambar 1. Metode Kegiatan Bakti Sosial}

Adapun masing-masing tahapan dari kegiatan pada gambar 1 diatas, yaitu :

1. Perencanaan Kegiatan, ditahapan ini dilakukan penentuan objek, tema dan sumber pendanaan.

2. Pelaksanaan Kegiatan, ditahapan ini ditentukan lokasi yang akan dilakukan pendistribusian paket. 
3. Evaluasi Kegiatan, ditahapan ini dilakukan evaluasi terhadap kegiatan yang telah dilakukan. Hasil evalusi ini menjadi rujukan untuk perbaikan kegiatan sejenis lainnya ke depan.

\section{Perencanaan}

Pada tahap perencanaan dilakukan penentuan objek, tema dan sumber pendanaan serta tim yang terlibat dalam kegiatan baksos. Objek tempat pelaksanaan ditentukan terdiri dari :

1. Graha Anak Yatim dan Dhuafa, beralamat di Kesambi Dalam No. 15/95, Kesambi, Drajat, Kec. Kesambi, Kota Cirebon, Jawa Barat 45134.

2. LKSA Siti Khodijah, beralamat di Satria Gg.Dahlia No.66B, RW.004/007, Kesambi, Kec. Kesambi, Kota Cirebon, Jawa Barat 45134.

3. Yayasan harapan Robbani, beralamat di Jl. Gelatik Raya No.3, Larangan, Kec. Harjamukti, Kota Cirebon, Jawa Barat 45141

4. Yayasan Al Kahfi, beralamat di Jl. Gn. Ciremai Giri No.E 6-7, Kecapi, Kec. Harjamukti, Kota Cirebon, Jawa Barat 45142.

Sedangkan tema pelaksanaan kegiatan bakti sosial adalah "Pahlawan Rumah Tangga, Pahlawanku Insprirasiku". Kegiatan ini bertepatan dengan pelaksanaan hari pahlawan 10 November 2021. Sumber pendanaan diperoleh dari seluruh sivitas akademika Universitas Catur Insan Cendekia.

\section{Pelaksanaan}

Pelaksanaan kegiatan ini selain bermitra dengan 4(empat) lembaga diatas juga untuk meningkatkan kepedulian mahasiswa dan Dosen Universitas Catur Insan Cendekia terhadap lingkungan masyarakat sekitar. Selain itu harapan tim pelaksana, dengan terlaksananya kegiatan ini, masyarakat dapat terbantu walaupun tidak dalam jumlah besar namun gerakan ini bisa meringankan beban bagi anak-anak yatim yang terbantu. Kegiatan ini berupa bakti sosial pembagian nasi kotak. Jumlah nasi box adalah sebanyak 358 paket. Pelaksanaan kegiatan dari UCIC terdiri dari himpunan mahasiswa dan dosen. Adapun perwakilan himpunan terdiri dari :

1. Mahasiswa yang tergabung dalam Himpunan Mahasiswa Manajemen Bisnis (HIMABIS) dan dosen-dosen pendamping.

2. Mahasiswa yang tergabung dalam Himpunan Mahasiswa Komputerisasi Akuntansi (HIMAKA), bersama dosen pendamping.
3. Mahasiswa yang tergabung dalam Himpunan Mahasiswa Teknik Informatika (HIMATIF), bersama dengan dosen pendamping,

4. Mahasiswa yang tergabung dalam Himpunan Mahasiswa Sistem Informasi (HIMASI) bersama dengan dosen pendamping.

5. Mahasiswa yang tergabung dalam Himpunan Mahasiswa Manajem (HIMAJEM) dan Himpunan Mahasiwa Akuntansi (HIMAKU), serta

6. Mahasiswa yang tergabung dalam Badan Koordinasi Mahasiswa (BKM).

Masing-masing himpunan mahasiswa didistribusikan ke empat tempat yang telah ditentukan sebelumnya.

\section{Evaluasi}

Evaluasi dari pelaksanaan kegiatan dilakukan melalui laporan kegiatan dan dipublikasi melalui akun Whatssapp Group Dosen Universitas Catur Insan Cendekia sebagai bukti pertanggunganjawaban kegiatan. Evaluasi juga dilakukan secara internal terkait model-model kegiatan kedepan, sponsorhip serta luaran akhir dari kegiatan tersebut.

\section{HASIL DAN PEMBAHASAN}

Sosialisasi kegiatan Pkm dilakukan melalui media sosial Instagram Universitas Catur Insan Cendekia serta media sosial himpunan yang ada di UCIC. Sosialisasi berisi informasi tentang paket nasi pahlawan beserta besaran nilai uangnya. Gambar 2, merupakan bentuk sosialisasi yang dilakukan di Instagram UCIC.

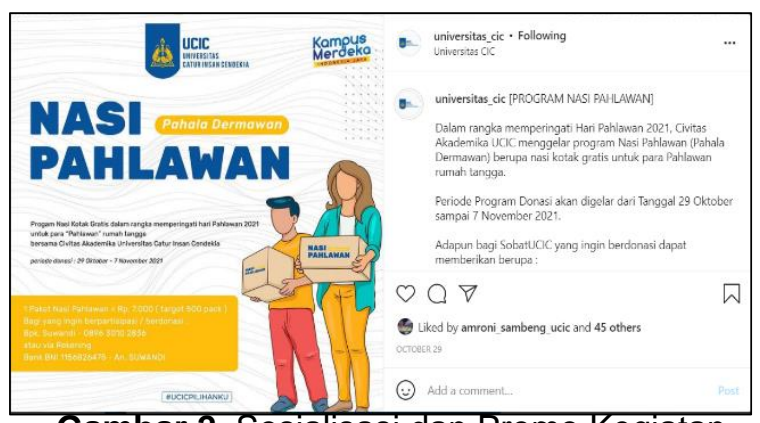

Gambar 2. Sosialisasi dan Promo Kegiatan

Pelaksanaan Pkm dengan Bakti sosial ini dilakukan oleh perwakilan himpunan mahasiswa manajemen bisnis (HIMABIS). HIMABIS untuk bakti sosial ini mendapatkan tempat di Graha Anak Yatim dan Dhuafa. Agenda kegiatan bakti sosial ini difokuskan pelaksanaannya bertepatan dengan hari pahlawan, yaitu ditanggal 10 Nopember 2021.Tabel 1, merupakan daftar agenda kegiatan bakti sosial tersebut. 
Tabel 1. Agenda Kegiatan Baksos.

\begin{tabular}{|c|c|}
\hline Hari/Tanggal & Kegiatan \\
\hline $\begin{array}{c}\text { Rabu/ } \\
10 \text { Nopember } 2021 \\
\text { (08.00 sd } 15.00 \\
\text { WIB })\end{array}$ & $\begin{array}{l}\text { 1. Pengarahan } \\
\text { untuk Persiapan } \\
\text { Kegiatan } \\
\text { 2. Penentuan } \\
\text { tempat untuk } \\
\text { baksos } \\
\text { 3. Distribusi Paket } \\
\text { Nasi Pahlawan. } \\
\text { 4. Dokumentasi } \\
\text { Kegiatan }\end{array}$ \\
\hline $\begin{array}{c}\text { Kamis / } \\
11 \text { Nopember } 2021\end{array}$ & $\begin{array}{l}\text { 1. Evaluasi kegiatan } \\
\text { 2.Penyusunan } \\
\text { Laporan Kegiatan }\end{array}$ \\
\hline
\end{tabular}

Kegiatan diawali dengan pengarahan dan sambutan yang dilakukan dihalaman utama kampus UCIC. Sambutan disampaikan oleh Kepala Biro Kemahasiswaan Universitas Catur Insan Cendekia (UCIC), Bapak Amroni, S.E.,M.M. Dalam sambutan disampaikan kembali tentang tema kegiatan yang akan dilaksanakan serta penentuan titik-titik untuk pendistribusian nasi pahlawan. Kegiatan pembukaan ini juga dihadiri oleh Dekan Fakultas yang ada di UCI, serta perwakilan dari dosen-dosen, ketua program studi dan tenaga kependidikan di UCIC.

Kegiatan selanjutnya pemberangkatan ke area tujuan. Untuk HIMABIS dilakukan di GRAY. Disana penerimaan disambut oleh perwakilan dari Graha Anak Yatim dan Dhuafa, terlihat seperti pada Gambar 3. Kegiatan selanjutnya adalah penyerahan 120 box paket Nasi Pahlawan untuk anak-anak yatim serta masyarakat yang menjadi pahlawan bagi anakanak yatim ini.

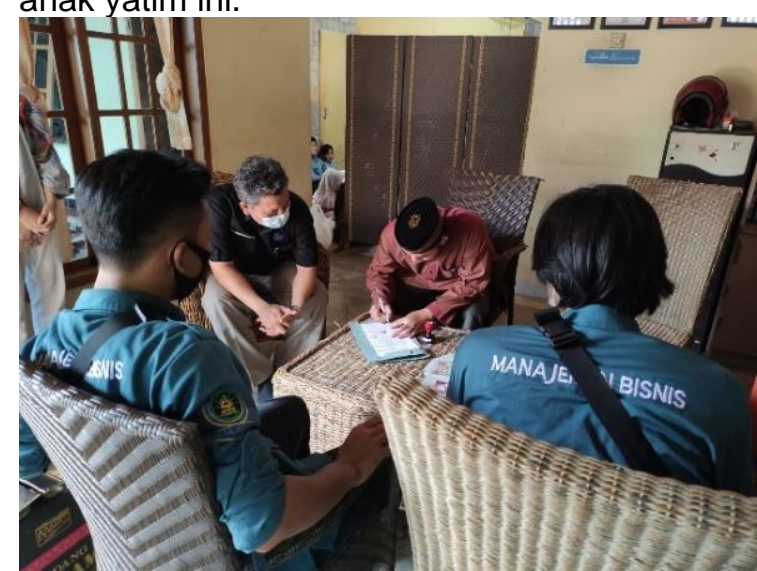

Gambar 3. Penerimaan BAKSOS dari GRAY

Pada Gambar 4 dan Gambar 5 serta Gambar 6, penyerahan secara simbolis paket "Nasi Pahlawan" kepada staff di Graha Anak Yatim dan Dhuafa Kota Cirebon. Beberapa perwakilan mahasiswa dari program studi manajemen bisnis yang hadir berjumlah 10 orang.

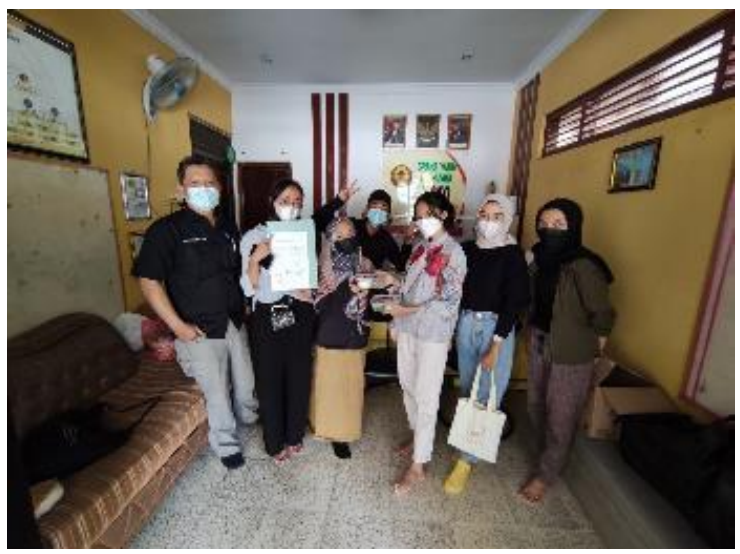

Gambar 4. Penyerahan Simbolis Nasi Pahlawan

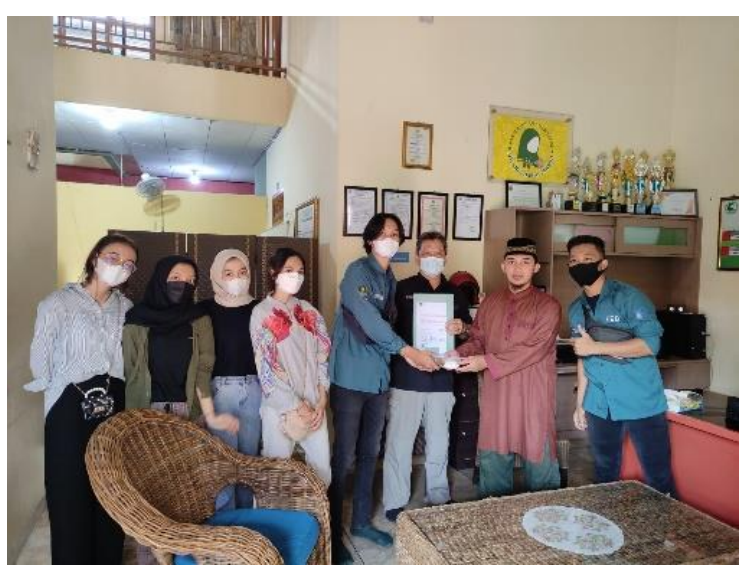

Gambar 5. Penyerahan Simbolis paket Nasi

Pahlawan kepada pengurus Graha Anak Yatim dan Dhuafa

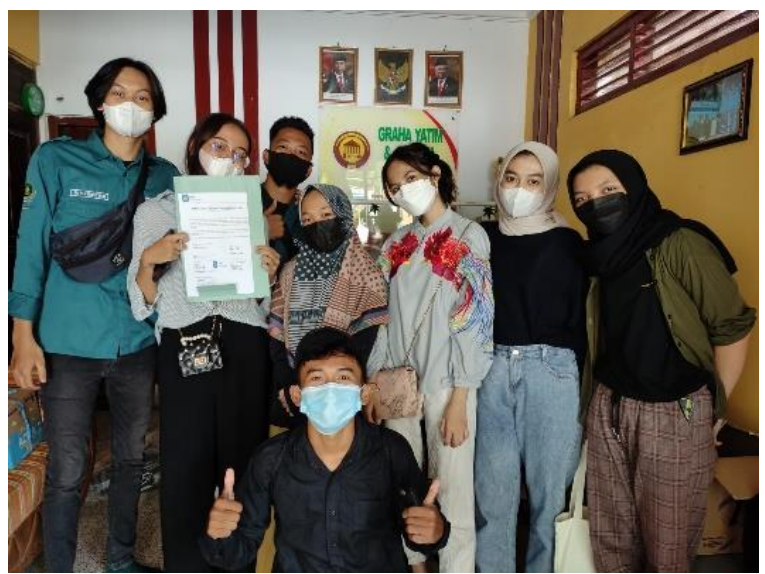

Gambar 6. Beberapa mahasiswa HIMABIS yang terlibat dalam kegiatan. 


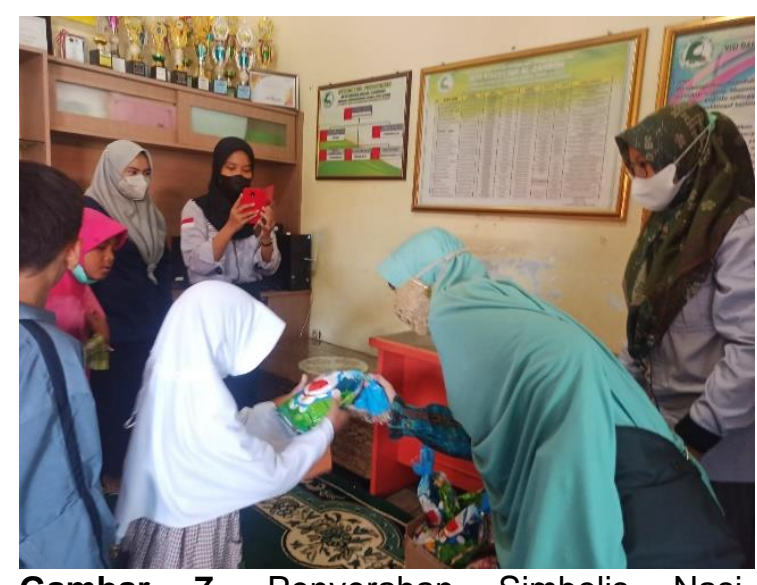

Gambar 7. Penyerahan Simbolis Nasi Pahlawan kepada Anak Yatim

\section{SIMPULAN}

Berdasarkan hasil kegiatan PKM yang telah dilakukan, maka dapat disimpulkan jika ; 1). Kegiatan Bakti Sosial dengan pemberian Paket Nasi Pahlawan merupakan salah satu kegiatan yang tepat dilakukan di masa pandemi Covid19. Di mana bisa sedikit meringankan beban masyarakat yang terdampak langsung dari situasi pandemi Covid-19 ini, 2). Melalui solidaritas antar dosen, karyawan serta mahasiswa UCIC, pelaksanaan pengabdian masyarakat ini dapat terlaksana dengan bai, 3). Kunjungan ke beberapa yayasan sosial, graha anak yatim dan dhuafa diharapkan dapat menumbuhkan rasa solidaritas yang tinggi bagi seluruh sivitas akademika yang terlibat didalam kegiatan ini, dan 4). Pelaksanaan kegiatan ini merupakan bentuk kontinuitas dari pelaksanaan kecendikiawan sivitas dilingkungan UCIC.

\section{UCAPAN TERIMAKASIH}

Terima kasih kepada seluruh sivitas akademika di UCIC yang terlibat secara lansung maupun tidak langsung, seperti dukungan sponsorhip, donasi dari dosen, staff dan tenaga kependidikan dilingkungan UCIC dalam mendukung keberhasilan pelaksanaan kegiatan ini.

\section{DAFTAR RUJUKAN}

Al-Faruqi, R. A., Roshidayah, R., Najmah, H., \& Fajri, R. N. (2020). KEGIATAN BAKTI SOSIAL UNTUK MEMBANTU EKONOMI LANSIA DI DESA JAMBEYAN PADA ERA NEW NORMAL. SELAPARANG Jurnal Pengabdian Masyarakat Berkemajuan, 4(1), $\quad$ 617-619. https://doi.org/10.31764/JPMB.V4l1.3369

Arafat, S., Rawe, A. S., Syariah, N., \& Abdullah,
A. N. (2021).
PENGABDIAN
MASYARAKAT GERAKAN BAKTI
SOSIAL PENYEMPROTAN
DISINFEKTAN DAN BERBAGI PAKET

Volume 5, Nomor 1, Desember 2021.

p-ISSN : 2614-5251

e-ISSN : 2614-526X

SANTUNAN PEDULI COVID-19 DI PONDOK PASENTRAN BUKIT TENGKORAK NDAO KABUPATEN ENDE FLORES. SELAPARANG Jurnal Pengabdian Masyarakat Berkemajuan, 4(3), 638-644. http://journal.ummat.ac.id/index.php/jpmb /article/view/4828

Cic.ac.id. (2021). Portal - Universitas Catur Insan Cendekia Cirebon. https://cic.ac.id/

GRAY. (2021). Graha Yatim dan Dhu'afa. https://grahayatimdhuafa.or.id/profil/sejar ah

Karlina, D., Agus, A., Paeno, P., \& Elfahmi, R. (2020). MENDAYAGUNAKAN PERAN KARANG TARUNA DALAM IMPLEMENTASI BAKTI SOSIAL MEMBANTU MENGURANGI BEBAN EKONOMI MASYARAKAT AKIBAT WABAH GLOBAL COVID-19 DI LINGKUNGAN RW 011 KELURAHAN PENGASINAN KOTA DEPOK. DEDIKASI PKM, 1(3), 73-78. https://doi.org/10.32493/DEDIKASIPKM. V113.6704

Kemensos. (2021). Logo Hari Pahlawan Tahun 2021 / Kementerian Sosial Republik Indonesia. https://kemensos.go.id/logohari-pahlawan-tahun-2021

Muniarty, P., Nurhayati, N., Wulandari, W., Rimawan, M., \& Amirulmukminin, A. (2021). Kegiatan Bakti Sosial Melalui Pembagian Sembako Kepada Masyarakat di Pandemi Covid-19. GLOBAL ABDIMAS: Jurnal Pengabdian Masyarakat, 1(1), 18-23. https://doi.org/10.51577/GLOBALABDIM AS.V111.74

Suwandi, S., Syafrinal, I., \& Asfi, M. (2021). RELIGIOUS TOURISM AND COMPENSATION TO ORPHANS TOGETHER WITH YAYASAN KREASI BANGUN SEMESTA CIREBON BRANCH. Indonesian Journal of Engagement, Community Services, Empowerment and Development, 1(2), 67-73. https://doi.org/10.53067/IJECSED.V112.1 1

Wikipedia. (2021). https://id.wikipedia.org/wiki/Pengabdian_ masyarakat 